\title{
Modern fat technology: what is the potential for heart health?
}

\author{
J. E. Upritchard*, M. J. Zeelenberg, H. Huizinga, P. M. Verschuren and E. A. Trautwein \\ Unilever Health Institute, Unilever Research and Development, PO Box 114, 3130 AC Vlaardingen, \\ The Netherlands
}

\begin{abstract}
Saturated and trans-fatty acids raise total cholesterol and LDL-cholesterol and are known to increase the risk of CHD, while dietary unsaturated fatty acids play important roles in maintaining cardiovascular health. Replacing saturated fats with unsaturated fats in the diet often involves many complex dietary changes. Modifying the composition of foods high in saturated fat, particularly those foods that are consumed daily, can help individuals to meet the nutritional targets for reducing the risk of CHD. In the 1960s the Dutch medical community approached Unilever about the technical feasibility of producing margarine with a high-PUFA and low-saturated fatty acid composition. Margarine is an emulsion of water in liquid oil that is stabilised by a network of fat crystals. In-depth expertise of fat crystallisation processes allowed Unilever scientists to use a minimum of solid fat (saturated fatty acids) to structure a maximum level of PUFA-rich liquid oil, thus developing the first blood-cholesterol-lowering product, Becel. Over the years the composition of this spread has been modified to reflect new scientific findings and recommendations. The present paper will briefly review the developments in fat technology that have made these improvements possible. Unilever produces spreads that are low in total fat and saturated fat, virtually free of trans-fatty acids and with levels of $n-3$ and $n-6$ PUFA that are in line with the latest dietary recommendations for the prevention of CHD. Individuals with the metabolic syndrome have a 2-4-fold increased risk of developing CHD; therefore, these spreads could make a contribution to CHD prevention in this group. In addition, for individuals with the metabolic syndrome the spreads could be further modified to address their unique dyslipidaemia, i.e. elevated blood triacylglycerols and low HDL-cholesterol. Research conducted in the LIPGENE study and other dietary intervention studies will deliver the scientific evidence to justify further modifications in the composition of spreads that are healthy for the heart disease risk factors associated with the metabolic syndrome.
\end{abstract}

Margarine: Saturated fats: Linoleic: $\alpha$-Linolenic: Trans-free: Polyunsaturated fats

More than twelve million people worldwide die annually from CVD, which is now the leading cause of death in Europe (British Heart Foundation Statistics, 2004). The most important type of CVD, in terms of mortality and morbidity, is CHD. Elevated total cholesterol (TC), LDL-cholesterol and triacylglycerols (TG) and low HDLcholesterol are associated with an increased risk of coronary events (Kannel et al. 1979; Martin et al. 1986; Assmann et al. 1996; Austin et al. 1998). It is well accepted that even small changes in blood lipid profiles can have important benefits for public health. A decrease in TC is associated with a reduction in the risk of CHD for all age-groups (Law et al. 1994). In general, a $1 \%$ decrease in TC is associated with a $1-2 \%$ reduction in risk.
Furthermore, a $1 \%$ decrease in LDL-cholesterol has been estimated to reduce the risk of major coronary events by $1.7 \%$ (4S study; Pedersen et al. 1998). Moreover, the relationship between the risk of heart disease and blood cholesterol levels is continuous and shows no threshold effect (MRFIT study; Dolecek, 1992).

Data from long-term primary and secondary intervention studies show that the risk of CHD is reduced when individuals change from a diet high in saturated fats to one high in PUFA (Dayton \& Pearce, 1969; Leren, 1970; Turpeinen, 1979; Hjermann et al. 1981; Miettinen et al. 1983; Jousilahti et al. 1998). Four large prospective cohort studies have shown a protective effect of total PUFA on CHD risk (Dolecek, 1992; Ascherio et al. 1996; 
Hu et al. 1997; Pietinen et al. 1997). The Nurses' Health Study (Hu et al. 1997), for example, indicates that replacement of $5 \%$ of the energy from saturated fatty acids (SFA) by PUFA could lower the risk of heart disease by $46 \%$. Part of the effect is almost certainly as a result of the beneficial effects on the blood lipid profile. However, it is not clear what proportion of the effect is attributable to the decrease in SFA or to the increase in PUFA.

SFA and unsaturated fatty acids have different effects on the balance of cholesterol-carrying lipoproteins in the blood (Keys, 1965; Hegsted et al. 1993; Clarke et al. 1997; Howell et al. 1997; Finnegan et al. 2003; Mensink et al. 2003). Several studies have evaluated the effectiveness of blood-cholesterol-lowering diets high in PUFA and low in SFA on coronary morbidity and mortality (Dayton et al. 1969; Leren, 1970; Turpeinen et al. 1979; Miettinen et al. 1983; Frantz et al. 1989). Overall, these studies have shown that diets low in SFA (8-9\% energy) and high in PUFA (14-21\% energy) reduce LDL-cholesterol levels by $13-15 \%$, which is associated with a $25-43 \%$ reduction in CHD events. In general, SFA increase TC, LDL-cholesterol and TG, while MUFA and PUFA decrease TC, LDLcholesterol and TG. Although both PUFA and MUFA lower TC:HDL-cholesterol, the effect of PUFA on TC and LDL-cholesterol is slightly superior to that of MUFA.

Worldwide mortality from heart disease is expected to continue to increase as a result of the ageing of the population and lifestyle changes linked to urbanisation, industrialisation and globalisation (World Health Organization, 2003). Physicans and healthcare professionals recommend individuals to change their diet to be low in saturated and trans-fats and higher in unsaturated fats to reduce their risk of CHD. Food manufacturers can contribute to this change by modifying the composition of food products. The present paper will review how advances in modern fat technology have allowed, for example, Unilever to update margarine and spread compositions in line with the latest scientific evidence.

Hippolyte Mège-Mouriès invented margarine in 1869 as a butter substitute. The Jurgens family purchased the patent 2 years later and started to manufacture margarine. At this time The Netherlands did not have patent legislation, thus it did not take long before a local competitor, van den Bergen, also started to produce margarine. After years of fierce competition the companies joined forces, resulting in a merger and the start of the Margarine Union in 1927. The Margarine Union signed an agreement with Lever Brothers 2 years later and became Unilever. The original beef-fat and milk recipe was adapted as new fats became available or cheaper and as a result of new technologies, such as fat hydrogenation and refrigeration. The drive behind these early innovations was to benchmark margarine with butter, both in appearance, structure, flavour and nutrition. Margarine was formulated to contain a similar level of fat, vitamin A and vitamin D to butter.

\section{Exchanging saturated fats for polyunsaturated fats}

In the 1960 s physicians and healthcare professionals began to recommend the use of oils rich in PUFA in order to decrease the saturated fat intake of patients with heart disease. However, individuals found it difficult in practice to exchange SFA for PUFA fats in their diet. Physicians, health care professionals and governmental organisations in The Netherlands concluded that there was a need for intervention at a population level and approached Unilever about the development of a margarine that was low in SFA but high in PUFA.

To make a margarine that was low in SFA but high in PUFA was a technical challenge for the food industry, as the particular fatty acids in margarine are an integral part of the structure of the product. Margarine is an emulsion of small water droplets in liquid oil stabilised by a structure of solid fat crystals (see Fig. 1). The solid fat crystals form a sponge-like structure that holds the oil in the product. The amount of solid fat crystals and their size, shape and mutual interaction, will influence the structure, hardness and texture of the product.

Many fats and oils from seeds, such as soyabean oil, sunflower-seed oil and rapeseed oil, are high in PUFA and low in SFA (see Fig. 2). However, these oils are too low in solids in the temperature range $10-35^{\circ} \mathrm{C}$ to give consistency to margarine. Tropical oils such as palm oil, palmkernel oil and coconut oil are higher in solids but they are also high in SFA. Alternatively, by altering the solid-phase characteristics of the oil (see Fig. 1), a low-SFA oil can be modified to provide more solids. The melting point of unsaturated oils and fats can be increased with hydrogenation, a process that converts unsaturated $\mathrm{C}=\mathrm{C}$ bonds in the fatty acid groups of the TG to saturated $\mathrm{C}-\mathrm{C}$ bonds, i.e. turning an unsaturated fat into a saturated fat. It was subsequently found that if the reaction is stopped when only some of the double bonds have reacted with $\mathrm{H}_{2}$ (partial hydrogenation) the products have different extents of saturation. Thus, the selection of the oil or fat, controlling the extent of saturation and optimising processing conditions such as $\mathrm{H}_{2}$ pressure, oil temperature, the choice of the catalyst, gives the partial hydrogenation technique the flexibility to produce fat-phase components with the desired characteristics from a range of oils. By applying this technology Unilever scientists were able to use a minimum of solid fat (SFA) to structure a maximum level of PUFA-rich liquid oil.

In 1960 Unilever developed the first blood-cholesterollowering product, Becel, which contained 50-55\% PUFA and could be used in place of butter in the diet. Originally, the product was distributed via pharmacies and during the first 3 years it could only be bought on medical prescription.

\section{Lowering the energy and the saturated fat}

In the late 1970s margarine manufacturers started to develop low-energy or 'light' spreads. The challenge was to develop a product with less than half the fat content, but with the same flavour, texture and spreading characteristics as the traditional product. Margarine is a water-in-oil emulsion that consists of $80 \%$ fat and $20 \%$ water (see Fig. 3). The fat level (80\%) has a historical background; butter also contains $80 \%$ fat. The microstructure of margarine consists of small water droplets in liquid oil 
(a)

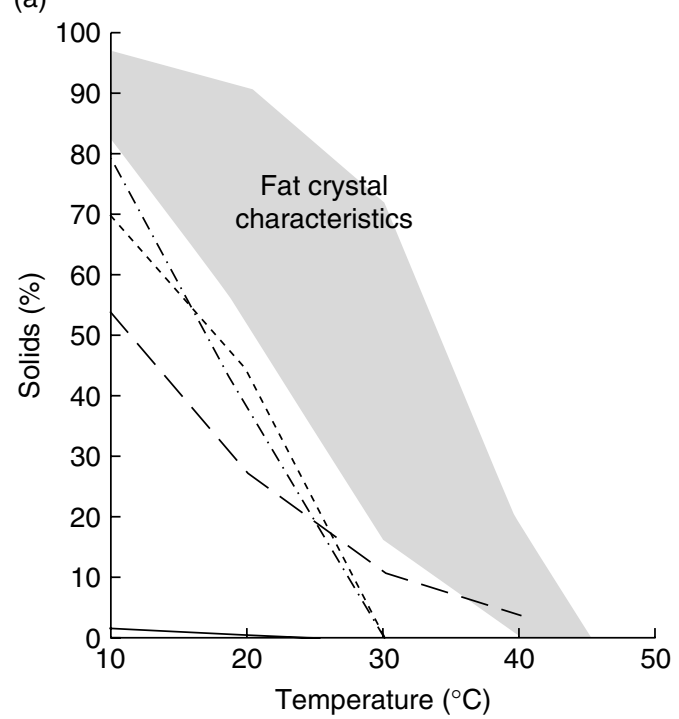

(b)

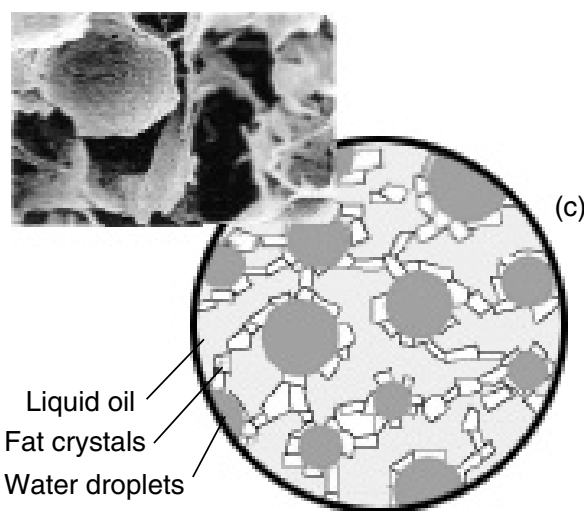

Fig. 1. (a) Production of margarine with optimised properties requires the availability of fats with a wide range of solid-phase characteristics ( $($ ); the oils and fats occurring in nature are too soft for most of these applications. The plot shows solid-phase characteristics for coconut $(-\cdot-\cdot-)$, palm kernel (----), palm oil (---) and sunflower-rapeseed (- - ). (b) Micrograph illustrating the structure of fat crystals whose characteristics are shown in the plot. (c) A representation of the structure of a margarine at $25^{\circ} \mathrm{C}$.

stabilised by a structure of solid fat crystals. The structure of low-fat margarine is comparable with that of full-fat margarine; however, four times the amount of water must be incorporated into the fat matrix. To achieve this level of incorporation technologists required a way of stabilising or structuring the water. Water can be structured by trapping it within a matrix of long molecular chains, as for example in jam or marmalade. Pectin, alginate and (modified) starches are commonly used to structure the water in lowfat spreads. An important characteristic of the structured aqueous phase is that the viscosity decreases at mouth temperature, to mimic the melting behaviour of high-fat spreads.

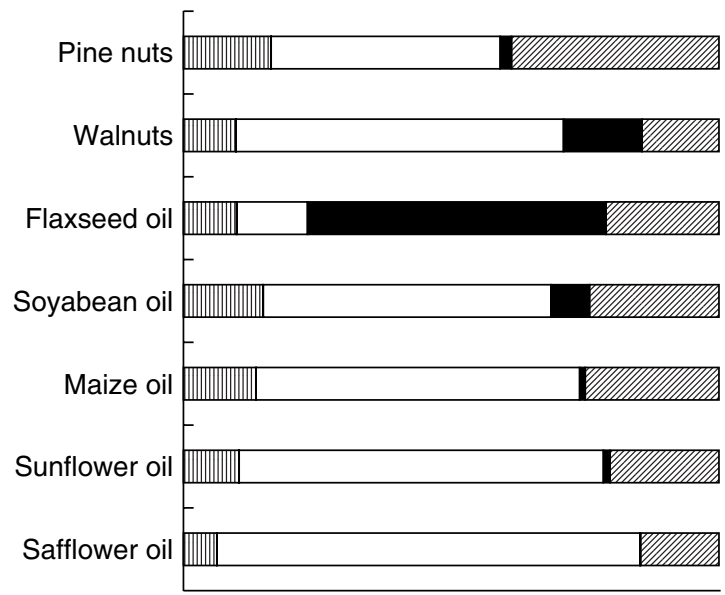

Fig. 2. Richest dietary sources of PUFA (\% total fat; US Department of Agriculture, 2002). (四), Saturated fat; ( $\square$ ), linoleic acid; (匹) linolenic acid; (四), monounsaturated fat.
The success or failure of 'light' products is determined by their taste; the 'light' product should taste as good as the ordinary product. Consumers expect the product to have the same quality attributes as their usual product; in the case of low-fat spreads flavour, product structure and water leakage are the key issues. The flavour associated with margarine is determined by added flavour compounds and salt. Traditionally, the flavour compounds used in margarine are partly soluble in fat and partly in water.

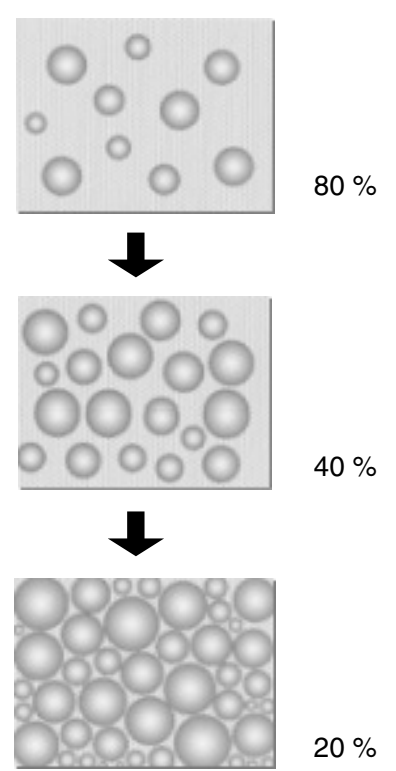

Fig. 3. Water-in-oil emulsion structure as found in spreads, showing the water that must be structured in $80 \%, 40 \%$ and $20 \%$ oil. 
There is an equilibrium between the level of flavour compounds in the product and that in the headspace (i.e. the air above the product in the packaging) of the product. These volatile components are responsible for the aroma of the product. As in low-fat spreads the proportion of water and oil is changed, and a new generation of flavour cocktails had to be developed for these products.

As rates of obesity in Europe have been steadily increasing over the past 50 years, resulting in more of the population with elevated blood cholesterol concentrations who are also overweight (World Health Organization, 2003), low-fat high-PUFA spreads are even more relevant at present. It is advised that weight loss is best achieved by reducing dietary energy intake and increasing physical activity (National Institutes of Health, 1998). However, weight loss per se appears to have little effect on TC and LDL-cholesterol and results in only minor improvements in serum TG and HDL-cholesterol concentrations (Yu-Poth et al. 1999). To improve weight management and blood lipid profiles the best results are achieved by the use of energy-restricted diets that are low in SFA and trans-fatty acids (TFA) in conjunction with increased physical activity (Expert Panel on Detection, Evaluation, and Treatment of High Blood Cholesterol in Adults, 2001).

As a result of the technological achievements in the area of low-energy spreads, low-fat versions of nearly all Unilever margarine brands became available in the 1970s. As low-fat spreads contain less fat, they also generally contain a lower SFA level compared with the high-fat versions. This reduction in SFA is possible because there is less liquid oil to structure and part of the product structure is now provided by the structured water phase. 'Light' versions of high-PUFA spreads, being low in SFA, perfectly fit with current recommendations for blood cholesterol management.

\section{Removal of trans-fats without increasing saturated fats}

In the 1990s evidence emerged showing deleterious effects of TFA on blood cholesterol concentrations. TFA and SFA have similar effects in raising blood TC and LDLcholesterol but TFA also lower HDL-cholesterol. Thus, CHD risk with TFA appears to be at least as bad as that with SFA (Willett et al. 1993). As a reaction to these new scientific findings, Unilever decided in 1995 to take the initiative and eliminate TFA from the fat-phase composition of margarine, and most European margarine manufacturers have now followed this decision.

In foods TFA originate from three major sources: bacterial transformation of unsaturated fatty acids in the rumen of ruminant animals (milk, butter and other dairy products, beef); hydrogenation (the process for increasing the solid fat crystals in unsaturated fats) and deodorization (the process for refining unsaturated vegetable and fish oils); when oils are heated to a high temperature (Food Standards Agency, 2004). Data from the TRANSFAIR study has shown that TFA levels in soft margarine in 1995-6 ranged between 1 and $17 \%$ in a survey of fourteen European countries (Food Standards Agency, 2004). Follow-up data from this study has shown the levels have

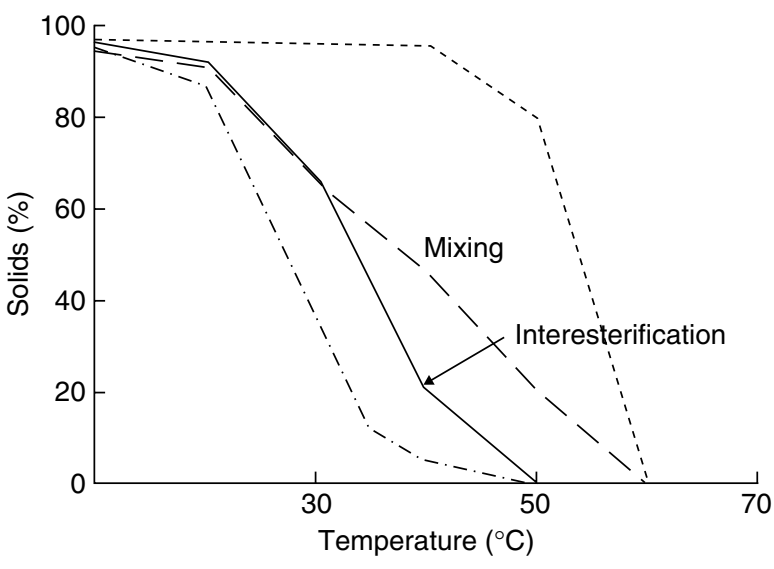

Fig. 4. Effect of interestification on the solid-phase characteristics for the product and its components. Two components $(-\cdot-\cdot-$, component $1 ;---$, component 2 ) are mixed (---, mixture) and then interesterified ( - , interesterified blend). The solid levels at high temperature decrease because of interesterification, while the solid levels at low temperature remain constant. The steepness of the solid-phase line for the product is improved (this effect will not always occur in this way, it depends on the fatty acid composition of the components of the interesterified mixture).

dropped to $<2 \%$, but in many cases this reduction has been achieved by an increase in SFA (Food Standards Agency, 2004). Presently, the effects of TFA on a $g$ per $g$ basis are considered to be worse than those of SFA, but usually the level of SFA in the diet is many-fold higher than that of TFA.

Unilever decided to eliminate TFA, but under the condition that SFA levels would not increase. The challenge for technologists was to increase the solids in unsaturated fats without using partial hydrogenation. Thus, other methods of modifying the solid-phase characteristics required development, such as fractionation, interesterification and hydrogenation. Fractionation is the controlled crystallisation of the 'solid' TG in a fat mixture followed by the separation of the solid and liquid fractions. The main oil that is fractionated worldwide is palm oil, mainly because of the demand for clear liquid oil (olein). More recently, there has been an interest in the solid product of fractionation of cocoa butter (stearin). Fractionation alone will produce a relatively soft stearin component that is not optimal for structuring margarine. However, fractionation followed by interesterification (see Fig. 4) is used to produce a fat phase suitable for margarine that does not contain hydrogenated components. Interesterification involves the rearrangement or redistribution of the fatty acid chains on the glycerol fragment of the TG molecule. This rearrangement can reduce the solids level at high temperature while maintaining the solids level at low temperature, making the solid-phase line steeper and the product better suited as a fat-phase component for margarine (see Fig. 4). Interesterification can be promoted by an alkaline catalyst or by lipase enzymes. Alkalinecatalysed reactions produce a mixture of TG in which the fatty acids are distributed randomly among the fat molecules and randomly among the three available positions within each molecule. In contrast, lipase is more 


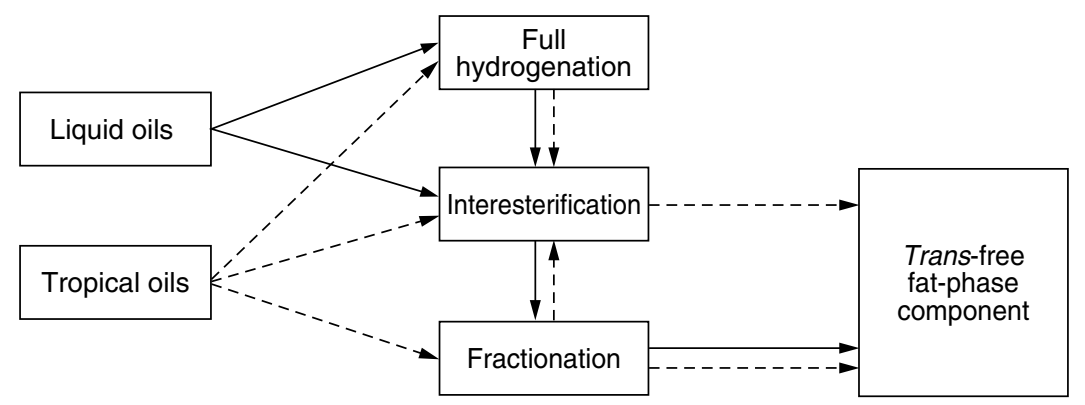

Fig. 5. Production of zero trans-fat-phase components with a range of melting points from liquid oils and tropical oils is possible by combination of full hydrogenation, interesterification and fractionation.

specific as it catalyses the rearrangement of the glycerol at the $s n-1$ and $s n-3$ position but leaves the ester link at the $s n-2$ position intact. The modification of the fatty acid distribution leads to an alteration in the solid-phase characteristics and the crystallisation behaviour. The actual change in solid-phase characteristics depends on the composition of the fatty acids included in the interesterified mixture. When interesterification is combined with fractionation a TFA-free margarine can be produced. Alternatively, liquid seed oils may be fully hydrogenated and while the TFA level remains very low $(<1 \%)$ they are subsequently interesterified with non-hydrogenated liquid oil to reduce the solids level at a high temperature. In some cases fractionation may also be used to further reduce the solids level. In addition, using tropical oils, with their relatively high level of solids, may create further flexibility in processing. This combination of techniques has created a tool for the production of optimal solid-fat components for margarine production, which is almost as flexible as partial hydrogenation (see Fig. 5). Thus, the elimination of TFA has been achieved without increasing the level of blood-cholesterol-raising SFA, while maintaining the margarine properties.

The transfer to TFA-free margarine production has been one of Unilever's major technical projects in the past decade, as it has involved the development of new fatphase compositions for $>600$ margarine blends while safeguarding the typical margarine characteristics.

\section{Getting a good fat balance}

Epidemiological evidence has shown a beneficial association between PUFA (specifically the $n-6$ PUFA linoleic acid) intake and CHD morbidity and mortality. Clinical studies have shown that $n-6$ PUFA have the most potent cholesterol-lowering effects of the individual fatty acid classes. More recently, researchers have started to examine the possible role of $n$-3 PUFA in reducing the risk of CHD. The most important dietary $n-3$ dietary PUFA are $\alpha$-linolenic acid (18:3n-3; ALA), EPA (20:5n-3) and DHA (22:6n-3). ALA is an essential fatty acid and is present in rapeseed oil, soyabean oil, linseed oil, walnuts and some seeds (see Fig. 2). EPA and DHA, which are often grouped together and referred to as very-long-chain PUFA, occur in oily fish and other marine animals. Furthermore, a small amount can be derived by conversion of dietary ALA (typically, only $1-10 \%$ of the ALA in the diet is converted to EPA and DHA); however, there is large variation between individuals, and conversion rates can be influenced by the dietary intake of linoleic acid and ALA (Goyens et al. 2005).

Diets high in ALA have been demonstrated to reduce the risk of CHD in several large cohort studies (Dolecek, 1992; Ascherio et al. 1996; Hu et al. 1997; Pietinen et al. 1997). Furthermore, a recent cross-sectional study in >1500 participants has found that higher intakes of ALA are inversely correlated with the occurrence of coronary artery disease (Djousse et al. 2003). Data from secondary intervention studies using ALA-rich mustard seed oil and Mediterranean-type diets enriched with ALA further support a beneficial effect on CVD (de Lorgeril et al. 1999).

Evidence from prospective secondary prevention studies suggests that EPA and DHA intakes ranging from 0.5 to $1.8 \mathrm{~g} / \mathrm{d}$ markedly reduce CHD mortality (Burr et al. 1989) and non-fatal myocardial infarction (Singh et al. 1997; Marchioli et al. 2002). Furthermore, a recent metaanalysis of eleven randomised controlled intervention trials with $>7900$ patients in the intervention groups has reported a reduction in overall mortality, mortality associated with myocardial infarction and sudden death in patients with CHD (Bucher et al. 2002). However, the evidence relating to the dose of EPA and DHA and the EPA:DHA that is protective for CHD is less clear, particularly in relation to primary prevention (Kris-Etherton et al. 2003; Hooper et al. 2004).

$n-3$ and $n-6$ PUFA may protect against CVD in different ways. Substituting PUFA for SFA or MUFA appears to protect against arrhythmia, thrombosis, haemostasis and inflammation, but the greatest effect is seen with $n-3$ longchain PUFA (EPA and DHA). In addition, high doses $(>3.5 \mathrm{~g} / \mathrm{d})$ of $n-3$ long-chain PUFA have been reported to reduce blood pressure and TG and increase HDLcholesterol but they do not lower LDL-cholesterol (KrisEtherton et al. 2003).

Current dietary guidelines make specific recommendations about the composition of PUFA that should be included in a healthy diet (see Table 1). It is recommended that total PUFA should contribute 4-10\% energy and linoleic acid between 4 and $8 \%$ energy. Recently, dietary guidelines have also included specific recommendations for $n-3$ PUFA such as ALA (2 g/d) and EPA and DHA 
Table 1. Dietary recommendation on fat intake in developed countries*

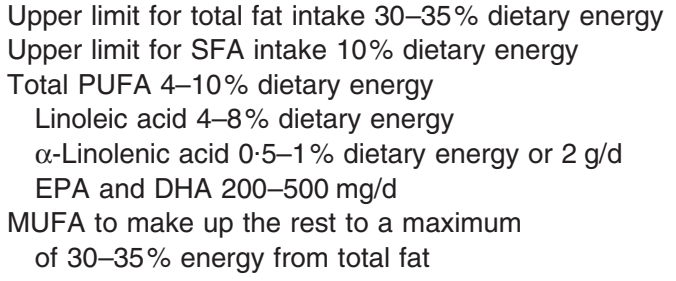

SFA, saturated fatty acids.

*Based on recommendations of Australia (National Health and Medical Research Council, 2003), Austria (Institute of Nutritional Sciences, 2003), Germany and Switzerland (German Nutrition Society, 2000), Belgium (National Council on Nutrition, 1997), Finland (National Nutrition Council, 1999), Sweden, Denmark and Norway (Sandström et al. 1996), Eurodiet (2001), FAO/WHO (Nishida et al. 2004) and USA (Department of Health and Human Sciences and Department of Agriculture, 2005). Not all countries have established recommendations for $\alpha$-linolenic acid and EPA and DHA.

$(0 \cdot 2-0 \cdot 5 \mathrm{~g} / \mathrm{d})$. Data from the TRANSFAIR study indicates that the current intake of $n-3$ PUFA (especially ALA) may be inadequate for a substantial proportion of the population (Hulshof et al. 1999). Thus, the composition of a good 'heart health' spread should contain appropriate amounts of linoleic acid and ALA.

However, when the level of ALA is increased at the expense of linoleic acid, the oil blend becomes more sensitive to oxidation; as the number of double bonds in the oil blend increases, it becomes more susceptible to oxidation. The technical challenge is to control oxidation during processing and storage. Auto-oxidation is a natural process that takes place between molecules of $\mathrm{O}_{2}$ and unsaturated fatty acids, and is initiated by light, metals and/or pro-oxidants (Frankel, 1998). The risk of oxidative reactions taking place during spread manufacture and storage is high, as they occur at the many interfaces between phases, e.g. water and oil, oil and fat crystals and at the air surface. To combat the oxidation risk, manufacturers use several techniques during formulation and processing. Antioxidants are added to protect the unsaturated fatty acids, and location of the antioxidant to the site where oxidation is occurring is important and primarily determined by the polarity of the antioxidant. Polar antioxidants are more effective in the bulk lipids whereas non-polar antioxidants are more effective in the dispersed lipids (Frankel, 1998). By selecting a range of antioxidants the lipids in the different phases can be protected. Iron, copper and other transition metals catalyse peroxidation of unsaturated fatty acids, but it is impossible to remove these metals from the manufacturing process as they are in many of the ingredients (e.g. oils, starch, milk proteins) and are usually present in water, as well as the equipment. In addition, oxidative reactions are influenced by temperature. Thus, by developing tight raw material specifications and strictly adhering to good manufacturing processes it is possible to keep oxidation to a minimum.

Another challenge to achieving a good balance between $n-3$ and $n-6$ fatty acids has been to find an oil that is sufficiently high in ALA. Nature only provides a limited range of oils. Rapeseed oil and linseed oil are the oils with the highest level of ALA (100 and $530 \mathrm{~g} / \mathrm{kg}$ respectively), but linseed oil is the only suitable oil to achieve the required ALA level in the product. However, linseed oil is not commonly used in the food industry, so it has been a challenge to set up a reliable supply chain. Furthermore, food authorities in some countries, being unfamiliar with this oil, have questioned its use in spreads and have had to be convinced of the safety and quality of linseed oil in this application.

\section{Future directions}

Over the years the composition of 'heart health' spreads has been constantly modified to implement new scientific findings and developments. Advances in modern fat technology have made many of these changes possible. Modifying a food product in line with current nutritional recommendations for preventing CHD provides consumers with an easy option for reducing their risk of CHD.

Spreads provide a convenient vehicle for regular intake of selected dietary compounds because they are typically consumed daily. 'Heart health' spreads help individuals to improve their blood lipid profiles, limit intakes of SFA and TFA and meet recommended intakes of the various PUFA. Spreads make an important contribution to dietary vitamin $\mathrm{A}$, vitamin $\mathrm{D}$, and vitamin $\mathrm{E}$. The benefit for blood lipids is greatest when the spreads replace SFA-rich products such as butter.

The metabolic syndrome is a clustering of metabolic abnormalities (dyslipidaemia, hypertension, visceral obesity and increased insulin resistance) that can lead to an increased risk of CVD and type 2 diabetes. The risk of CVD is 2-4-fold higher in individuals with the metabolic syndrome, which makes strategies to reduce CVD risk a main focus in the treatment of these individuals. For individuals with the metabolic syndrome the spreads could be further modified to address their unique dyslipidaemia. Research conducted in the LIPGENE study and other dietary intervention studies will deliver the scientific evidence to justify further modifications in the composition of 'heart health' spreads.

\section{References}

Ascherio A, Rimm EB, Giovannucci EL, Spiegelman D, Stampfer M \& Willett WC (1996) Dietary fat and risk of coronary heart disease in men: cohort follow up study in the United States. British Medical Journal 313, 84-90.

Assmann G, Schulte H, von Eckardstein A \& Huang Y (1996) High-density lipoprotein cholesterol as a predictor of coronary heart disease risk. The PROCAM experience and pathophysiological implications for reverse cholesterol transport. Atherosclerosis 124, Suppl., S11-S20.

Austin MA, Hokanson JE \& Edwards KL (1998) Hypertriglyceridemia as a cardiovascular risk factor. American Journal of Cardiology 81, 7B-12B.

British Heart Foundation Statistics (2004) CHD 2004: Mortality chapter. http://www.heartstats.org/temp/Mortalityspchapter.pdf

Bucher HC, Hengstler P, Schindler C \& Meier G (2002) N-3 polyunsaturated fatty acids in coronary heart disease: a metaanalysis of randomized controlled trials. American Journal of Medicine 112, 298-304. 
Burr ML, Fehily AM, Gilbert JF, Rogers S, Holliday RM, Sweetnam PM, Elwood PC \& Deadman NM (1989) Effects of changes in fat, fish, and fibre intakes on death and myocardial reinfarction: diet and reinfarction trial (DART). Lancet ii, $757-761$.

Clarke R, Frost C, Collins R, Appleby P \& Peto R (1997) Dietary lipids and blood cholesterol: quantitative meta-analysis of metabolic ward studies. British Medical Journal 314, 112-117.

Dayton S \& Pearce ML (1969) Prevention of coronary heart disease and other complications of arteriosclerosis by modified diet. American Journal of Medicine 46, 751-762.

Dayton S, Pearce M \& Hashimoto S (1969) A controlled clinical trial of a diet high in unsaturated fat in preventing complications of atherosclerosis. Circulation 40, S11-S63.

De Lorgeril M, Salen P, Martin JL, Monjaud I, Delaye J \& Mamelle N (1999) Mediterranean diet, traditional risk factors, and the rate of cardiovascular complications after myocardial infarction: final report of the Lyon Diet Heart Study. Circulation 99, 779-785.

Department of Health and Human Sciences and Department of Agriculture (2005) Dietary guidelines for Americans. http:// www.healthierus.gov/dietaryguidelines/ (accessed February 2005).

Djousse L, Folsom AR, Province MA, Hunt SC \& Ellison RC (2003) Dietary linolenic acid and carotid atherosclerosis: the National Heart, Lung, and Blood Institute Family Heart Study. American Journal of Clinical Nutrition 77, 819-825.

Dolecek TA (1992) Epidemiological evidence of relationships between dietary polyunsaturated fatty acids and mortality in the multiple risk factor intervention trial. Proceedings of the Society for Experimental Biology and Medicine 200, 177-182.

Eurodiet (2001) Eurodiet core report. Nutrition and diet for healthy lifestyles in Europe: science and policy implications. Public Health Nutrition 4, 265-273.

Expert Panel on Detection, Evaluation, and Treatment of High Blood Cholesterol in Adults (2001) Executive summary of the third report of the National Cholesterol Education Program (NCEP) Expert Panel on Detection, Evaluation, and Treatment of High Blood Cholesterol in Adults (Adult Treatment Panel III). Journal of the American Medical Association 285, 2486-2497.

Finnegan YE, Howarth D, Minihane AM, Kew S, Miller GJ, Calder PC \& Williams CM (2003) Plant and marine derived (n-3) polyunsaturated fatty acids do not affect blood coagulation and fibrinolytic factors in moderately hyperlipidemic humans. Journal of Nutrition 133, 2210-2213.

Food Standards Agency (2004) European Food Standards Agency Opinion. EFSA-Q-2003-022. London: FSA.

Frankel E (1998) Lipid Oxidation. Bridgewater, Somerset: PJ Barnes \& Associates.

Frantz ID Jr, Dawson EA, Ashman PL, Gatewood LC, Bartsch GE, Kuba K \& Brewer ER (1989) Test of effect of lipid lowering by diet on cardiovascular risk. The Minnesota Coronary Survey. Arteriosclerosis 9, 129-135.

German Nutrition Society (2000) Referenzwertefür die Nährstoffzuhr (Reference Values for Nutrient Intake). Bonn, Germany: DGE-Medien Service.

Goyens PL, Spilker ME, Zock PL, Katan MB \& Mensink RP (2005) Development of a compartmental model to quantify alpha-linolenic acid conversion after longer-term intake of multiple tracer boluses. Journal of Lipid Research (In the Press).

Hegsted DM, Ausman LM, Johnson JA \& Dallal GE (1993) Dietary fat and serum lipids: an evaluation of the experimental data. American Journal of Clinical Nutrition 57, 875-883.

Hjermann I, Velve BK, Holme I \& Leren P (1981) Effect of diet and smoking intervention on the incidence of coronary heart disease. Report from the Oslo Study Group of a randomised trial in healthy men. Lancet ii, 1303-1310.

Hooper L, Thompson RL, Harrison RA, Summerbell CD, Moore $\mathrm{H}$, Worthington HV et al. (2004) Omega 3 fatty acids for prevention and treatment of cardiovascular disease. The Cochrane Database of Systematic Reviews 2004, issue 4 CD003177. http://www.mrw.interscience.wiley.com/cochrane/ clsysrev/articles/CD003177/frame.html

Howell WH, McNamara DJ, Tosca MA, Smith BT \& Gaines JA (1997) Plasma lipid and lipoprotein responses to dietary fat and cholesterol: a meta-analysis. American Journal of Clinical Nutrition 65, 1747-1764.

Hu FB, Stampfer MJ, Manson JE, Rimm E, Colditz GA, Rosner BA, Hennekens CH \& Willett WC (1997) Dietary fat intake and the risk of coronary heart disease in women. New England Journal of Medicine 337, 1491-1499.

Hulshof KFAM, van Erp-Baart MA, Anttolainen M, Becker W, Church SM, Couet C et al. (1999) Intake of fatty acids in Western Europe with emphasis on trans fatty acids: The TRANSFAIR study. European Journal of Clinical Nutrition 53, 143-157.

Institute of Nutritional Sciences (2003) Austrian Nutrition Report. Vienna, Austria: Federal Ministry of Health and Women.

Jousilahti P, Vartiainen E, Pekkanen J, Tuomilehto J, Sundvall J \& Puska P (1998) Serum cholesterol distribution and coronary heart disease risk: observations and predictions among middle-aged population in eastern Finland. Circulation 97, 1087-1094.

Kannel WB, Castelli WP \& Gordon T (1979) Cholesterol in the prediction of atherosclerotic disease. New perspectives based on the Framingham study. Annals of Internal Medicine $\mathbf{9 0}$, 85-91.

Keys A (1965) Effects of different dietary fats on plasma lipid levels. Lancet i, 318-319.

Kris-Etherton PM, Harris WS \& Appel LJ (2003) Omega-3 fatty acids and cardiovascular disease: new recommendations from the American Heart Association. Arteriosclerosis, Thrombosis, and Vascular Biology 23, 151-152.

Law MR, Wald NJ \& Thompson SG (1994) By how much and how quickly does reduction in serum cholesterol concentration lower risk of ischaemic heart disease? British Medical Journal 308, 367-373.

Leren P (1970) The Oslo diet-heart study. Eleven-year report. Circulation 42, 935-942.

Marchioli R, Barzi F, Bomba E, Chieffo C, Di Gregorio D, Di Mascio R et al. (2002) Early protection against sudden death by $n-3$ polyunsaturated fatty acids after myocardial infarction: time-course analysis of the results of the Gruppo Italiano per lo Studio della Sopravvivenza nell'Infarto Miocardico (GISSI)Prevenzione. Circulation 105, 1897-1903.

Martin MJ, Hulley SB, Browner WS, Kuller LH \& Wentworth D (1986) Serum cholesterol, blood pressure, and mortality: implications from a cohort of 361,662 men. Lancet ii, 933-936.

Mensink RP, Zock PL, Kester AD \& Katan MB (2003) Effects of dietary fatty acids and carbohydrates on the ratio of serum total to HDL cholesterol and on serum lipids and apolipoproteins: a meta-analysis of 60 controlled trials. American Journal of Clinical Nutrition 77, 1146-1155.

Miettinen M, Turpeinen O, Karvonen MJ, Pekkarinen M, Paavilainen E \& Elosuo R (1983) Dietary prevention of coronary heart disease in women: the Finnish mental hospital study. International Journal of Epidemiology 12, 17-25.

National Council on Nutrition (1997) Voedingesaanbe Verlingen voor Belgie (Dietary Recommendation for Belgium). Ministry of Social Affairs, Public Health and Environment Publication no. D/1996/7795/12. Brussels, Belgium: Ministry of Social Affairs, Public Health and Environment. 
National Health and Medical Research Council (2003) Dietary Guidelines for Australian Adults. Canberra, ACT: National Health and Medical Research Council.

National Institutes of Health (1998) Clinical Guidelines on the Identification, Evaluation, and Treatment of Overweight and Obesity in Adults. NIH Publication no. 98-4083. Bethesda, MA: NIH, National Heart, Lung and Blood Institute.

National Nutrition Council (1999) Finnish Nutritional Recommendations. Helsinki, Finland: Ministry of Agriculture and Forestry.

Nishida C, Uauy R, Kumanyika S \& Shetty P (2004) The Joint WHO/FAO Expert Consultation on diet, nutrition and the prevention of chronic diseases: process, product and policy implications. Public Health Nutrition 7, 245-250.

Pedersen TR, Olsson AG, Faergeman O, Kjekshus J, Wedel H, Berg K et al. (1998) Lipoprotein changes and reduction in the incidence of major coronary heart disease events in the Scandinavian Simvastatin Survival Study (4S). Circulation 97, 1453-1460.

Pietinen P, Ascherio A, Korhonen P, Hartman AM, Willett WC, Albanes D \& Virtamo J (1997) Intake of fatty acids and risk of coronary heart disease in a cohort of Finnish men. The AlphaTocopherol, Beta-Carotene Cancer Prevention Study. American Journal of Epidemiology 145, 876-887.

Sandström B, Lyhne N, Petersen JI, Aro A, Thorsdóttir I \& Becker W (1996) Nordic nutrition recommendations. Scandinavian Journal of Nutrition 40, 161-165.
Singh RB, Niaz MA, Sharma JP, Kumar R, Rastogi V \& Moshiri M (1997) Randomized, double-blind, placebo-controlled trial of fish oil and mustard oil in patients with suspected acute myocardial infarction: the Indian experiment of infarct survival-4. Cardiovascular Drugs and Therapy 11, 485-491.

Turpeinen O (1979) Effect of cholesterol-lowering diet on mortality from coronary heart disease and other causes. Circulation 59, 1-7.

Turpeinen O, Karvonen MJ, Pekkarinen M, Miettinen M, Elosuo R \& Paavilainen E (1979) Dietary prevention of coronary heart disease: the Finnish Mental Hospital Study. International Journal of Epidemiology 8, 99-118.

US Department of Agriculture (2002) USDA National Nutrient Database for Standard Reference, release 15. http://www.nal. usda.gov/fnic/foodcomp (accessed January 2005).

Willett WC, Stampfer MJ, Manson JE, Colditz GA, Speizer FE, Rosner BA, Sampson LA \& Hennekens CH (1993) Intakes of trans fatty acids and risk of coronary heart disease among women. Lancet 341, 581-585.

World Health Organization (2003) Diet, Nutrition and the Prevention of Chronic Diseases. Joint WHO/FAO Expert Consultation. WHO Technical Report Series no. 916. Geneva: WHO.

Yu-Poth S, Zhao G, Etherton T, Naglak M, Jonnalagadda S \& Kris-Etherton PM (1999) Effects of the National Cholesterol Education Program's Step I and Step II dietary intervention programs on cardiovascular disease risk factors: a metaanalysis. American Journal of Clinical Nutrition 69, 632-646. 